\title{
AUSENCIAS EN EL CANON DE LA NARRATIVA ACTUAL: SANTIAGO RODRÍGUEZ SANTERBÁS
}

\author{
Leonardo ROMERo TOBAR \\ Universidad de Zaragoza
}

Causas de la más diversa naturaleza explican las ausencias de escritores y obras de mérito indudable en los repertorios canónicos de cualquier género o época histórico-literaria: pérdida de textos, desinterés de los lectores, desvalorización de temas o géneros, empleo de lenguas distintas del español, desconfianza estética, censuras ideológicas o de intereses empresariales, pereza intelectual... Por ello la escritura de una «Historia de la Literatura Española» sigue siendo un telar abierto e inconcluso, una construcción en marcha a la que los descubrimientos de lo ignorado le confieren un dinamismo vivo y estimulante.

El análisis de cada una de las causas que han motivado o que siguen produciendo los aludidos vacíos me llevaría muy lejos del propósito que guía las páginas que siguen, dedicadas a exponer la obra literaria de un escritor actual que, como otros muchos, es un mero nombre en las listas al uso de novelistas españoles del último cuarto de siglo XX, a pesar de que su obra publicada es una original y valiosa contribución al progreso del género. El porqué haya sido así, puede obedecer a muchos motivos, entre los que no se me ocultan los tropismos profesionales que conducen a críticos e historiadores a repetir esquemas interpretativos en los que las «tendencias» y los nombres habituales ofrecen un cómodo decir para quienes prefieren transitar por caminos ya rodados.

El silencio crítico que se ha cernido sobre Santiago Rodríguez Santerbás (nacido en Burgos en 1937) es análogo al olvido o la rapidez con los que son despachados en repertorios informativos, panoramas y libros de consul- 
ta otros valiosos narradores de una edad próxima a la suya. En las fuentes informativas sobre narrativa actual son pocas las noticias y mínimas las estimaciones que se leen acerca de novelistas como Manuel Derqui (Meterra fue edición póstuma de 1975), Ángel Vázquez, autor entre otras novelas, de La vida perra de Juanita Narboni, aparecida 1976 o, más más cercano al momento actual, de Luciano G. Egido (El cuarzo rojo de Salamanca es de 1993). He citado estos tres casos a título de ejemplo abreviado y para repetir el modelo de las «tendencias narrativas» que representan estas novelas, del relato expresionista la primera, del monólogo interior la segunda y de la novela histórica la última. Otra perspectiva ofrecen rescates como el descubrimiento póstumo, en circuitos minoritarios, de narradores como Miguel Espinosa (nacido en 1926), afortunadamente incluido al fin en el «canon» gracias a la atención crítica que le han prestado exigentes lectores vinculados al escenario geográfico en el que se movió el escritor murciano. Diversas circunstancias del mercado y la difusión de los libros explicarían los «descubrimientos» recientes de novelistas que llevaban tiempo publicando (José Esteban, Carlos Pujol, Javier Tomeo...).

Para Santiago Rodríguez Santerbás ni siquiera los centones bio-bibliográficos de carácter local o autonómico le han dedicado un mínimo espacio ${ }^{1}$, siendo autor de una pieza teatral, cuadernos gastronómicos, varias novelas cortas, tres relatos extensos y una docena de muy cuidadas traducciones de textos ensayísticos y narrativos ingleses y franceses ${ }^{2}$. Sólo en algunas páginas redactadas por amigos con los que Rodríguez Santerbas ha compartido complicidades artísticas podemos leer estimaciones sobre las características y significación de su obra literaria ${ }^{3}$, y todo ello contra el pronóstico que sentaba en 1960 Miguel Delibes en el prólogo que escribió para Jorobita, la primera narración editada de nuestro autor: «Tengo la impresión de que Santiago Rodríguez Santerbás va a dar que hablar en el campo literario nacional» ${ }^{4}$. Por aquellas fechas el escritor burgalés escribía en periódicos

1. Es un nombre más que se cita en el volumen Literatura actual en Castilla y León (José María Balcells coordinador, Valladolid, Ámbito Ediciones, 2005, p. 663) y una breve ficha en el Diccionario de la cultura en Burgos. Siglo XX de Fernando Ortega Barriuso (Burgos, Dossoles, 2001, p. 575).

2. Rodríguez Santerbás ha traducido Frashwater (1980) de Virginia Woolf, La casa ideal y otros textos (19080) de Robert Louis Stevenson, Una disertación sobre el cochinillo asado (1982) de Charles Lamb, Una excursión fotográfica (1983) de Lewis Caroll, Canción de Navidad (1986) de Dickens, La muerta enamorada (1986) de Théophile Gautier, Oraciones de Vailima y Sermón de Navidad (1986) de Robert Louis Stevenson, Silvia y Bruno (1989) de Lewis Carroll, El sabueso de los Baskerville (1989) de Arthur Conan Doyle, Fabuleario (1993) de Edward Lear.

3. Véanse el «Prólogo» de Miguel Delies a Jorobita (1960) y la «Introducción» y el «Apéndice» que acompañan a la segunda edición de Tres pastiches victorianos (1996) firmados respectivamente por los conocidos críticos cinematográficos Juan Tébar y Eduardo Torres-Dulce.

4. Miguel Delibes, en Jorobita, p. 10. 
castellanos -El Norte de Castilla y Diario de Burgos-, de los que pasó a ser colaborador habitual en la revista Triunfo donde firmaba trabajos de crítica artística, musical y literaria y en los que mostró poseer un conocimiento y competencia crítica inusitados en la época ${ }^{5}$.

Las notas informativas que acompañan a las primeras publicaciones de nuestro autor se refieren a novelas cortas suyas que habían quedado bien clasificadas en concursos literarios; yo no he conseguido leer las aludidas en esas notas -Los perros muertos y El camino de las sirenas- ni la colección de relatos breves La muerte bien temperada a que se refiere TorresDulce como libro inédito en 1996. Y de muy difícil localización es la corta tirada de cien ejemplares que tuvo Valdediós (1987), una miscelánea de géneros bellamente editada por la gijonesa galería de Arte Cornión, y que obtuvo el Premio Nacional de edición de aquel año.

La voluntad de belleza en la presentación editorial de sus publicaciones y la plétora de saberes culturales de muy diversa naturaleza caracterizan, en una primera aproximación, la obra literaria de Rodríguez Santerbás. Su idea del libro bello como un arte total se aprecia, por ejemplo, en la única pieza escénica que le conozco, La doncella y el unicornio (1989), estampa de teatro poético en la que el texto va acompañado de ilustraciones gráficas firmadas por Sara R. Chamón y de ilustraciones musicales de Elena R. Chamón, hijas ambas de escritor y cuya «R» de la firma «se trata de un family affair, una conspiración familiar de indudable buen resultado» ${ }^{6}$.

En esta pieza, publicada en la colección de literatura juvenil de una conocida editorial especializada en libros escolares ${ }^{7}$, un preámbulo en verso que canta el Trovador a telón corrido, pergeña al modo costumbrista el escenario de un palacio real y el perfil de los personajes principales de una trama que se resuelve con quiebro poético en el rechazo de la princesa al pretendiente que, originariamente, había sido un unicornio del que ella había quedado prendada:

La doncella se fue/ con su blanco vestido,/ los ojos muy abiertos/ y el corazón cansado./ No fue a recoger flores,/ ni a buscar un marido;/ fue a soñar unicornios/ en el bosque hechizado ${ }^{8}$.

5. En la digitalización de la revista Triunfo <http://www.triunfodigital.com> se recogen artículos de nuestro autor.

6. E. Torres-Dulce, op. cit., p. 192.

7. El propio escritor era miembro de una familia titular de otra firma editorial muy acreditada también en la producción de textos escolares.

8. La doncella y el unicornio, p. 44. 


\section{LA OBRA NARRATIVA DE RoDRÍGUEZ SANTERBÁS}

El refinado culturalismo que impregna los relatos de Santiago Rodríguez Santerbás no fue, desde luego, la excepción madrileña a la invención periodística de la que fue llamada «escuela de la berza» mesetaria . Rodríguez Santerbás, como otros muchos escritores españoles formados en los años de la inmediata postguerra, tanto del centro geográfico como de la periferia, buscó la salvación de su mundo interior en la lectura voraz y en los viajes al extranjero, dos formas de eludir la inhóspita realidad española de mediados del siglo XX. Con estos recursos fabricó, en mi opinión, las paredes maestras de sus obras narrativas. La integración, pues, de las Bellas Artes en sus relatos -como ocurre en la pieza teatral a la que me he referido- es un recurso paralelo a la intensificación de citas intertextuales y guiños devotos a las buenas formas sociales de los países europeos y al distanciamiento irónico con el que es encarada la vida cotidiana espejeada en las páginas de sus relatos ${ }^{9}$. Sí puede apreciarse, con todo, una intensificación de esos artificios constructivos en el curso del avance cronológico de su escritura, ya que en su primer relato Jorobita predomina una sencilla veta de irrealidad poética que se irá hipertrofiando en los textos posteriores.

Desde luego, el juicio de Miguel Delibes sobre la contención estilística que caracterizaba los primeros relatos de Santiago Rodríguez Santerbás y en los que se revelaba como «un hábil administrador de palabras, como un joven maestro de economía literaria», creo que solo se puede aplicar al último del que tengo noticia, Román y yo (1987), ya que en los años intermedios de su producción la abundancia de artificios literarios es mucho más llamativa, como puede comprobarse en los libros titulados Tres pastiches victorianos (1980), La vuelta al mudo en ochenta días (1982) y La inmortalidad del cangrejo (1985).

9. Valgan como muestras de este tratamiento sarcástico de la vida española del momento dos breves pasajes de La inmortalidad de cangrejo: «Desfilaban los últimos encapuchados; ambas hileras se juntaban en una línea transversal de cinco capirotes; el del centro era sin duda el jefe o preboste de la cofradía (...). La momentánea claridad de un relámpago bañó las capas pluviales y las dalmáticas de los clérigos que marchaban en pos de la imagen; y el trueno subsiguiente se multiplicó, como un eco prolongado, en el redoble de los tambores que tañían quince o veinte sujetos disfrazados de legionarios de la antigua Roma. Un tropel de mujeres enlutadas venía detrás de los soldados romanos, algunas caminaban descalzas y velaban sus rostros con gasas negras; otras mantenían sus brazos extendidos en forma de cruz. Una voz de falsete inició la primera estrofa de un cántico penitencial, y el coro de las enlutadas se adhirió mecánicamente a la deprecación: Perdona a tu pueblo, Señor/ perdona a tu pueblo/ perdónale, Señor. Un nuevo relámpago deslumbró a las suplicantes» (p. 61). «El dieciocho de julio, con las formalidades acostumbradas, celebramos el octogésimo primer cumpleaños de tío Camilo, y él se obsequió a sí mismo con un raro ejemplar de la Mona Hieroglyphica de John Dee» (p. 118). 
Efectivamente, Jorobita narra la biografía de un toro malforme - «Jorobita nació en enero. Lo trajo una cigüeña y lo dejó, acurrucadito y húmedo, junto a la madre»- que crece aislado de la manada y para el que los contactos afectivos son reducidos y episódicos. Una noche, en que fue trasteado por un maletilla, dejó huella profunda en su memoria, y aquel torerillo es el que lo torea y lo remata magistralmente al final del relato. Los toques de ambientación maravillosa que van subrayando la narración tienen correspondencia en la novelística fantástica representada por las Industrias $y$ andanzas de Alfanhuí (1951) de Sánchez Ferlosio ${ }^{10}$, y el escueto estilo sintáctico remite a los modelos prosísticos azorinianos que todavía lucraban de prestigio entre escritores de mediados de la pasada centuria. Esta sencillez en la prosa coincide, además, con el rápido trazado de los dibujos que acompañan al texto, varios grabados firmados por «Rodríguez Santerbás», los apellidos del escritor que serán metamorfoseados posteriormente en otros impresos por la firma «J. Isaac», nombre propio que forma parte también de la onomástica del autor.

Las ilustraciones que llevan este segundo nombre las encontramos en libros que, como Tres pastiches victorianos y La vuelta al mundo en ochenta mundos, revisten mayor elaboración estilística y una complejidad narrativa que se hace patente en el diseño editorial de ambas obras, un aspecto en el que siempre se ha esmerado nuestro autor y al que, no sé si desde presupuestos semióticos o desde simples imperativos de buen gusto, ha prestado singular cuidado en lo relativo a los materiales paratextuales de sus relatos. Desde luego, en el diseño gráfico de la cubierta que, firmada por él o por otros dibujantes, sitúa al lector ante el artefacto literario con el que se va a encontrar. Y, en grado eminente, en las numerosas apostillas explicativas o exegéticas que acompañan a las narraciones.

En Tres pastiches victorianos Rodríguez Santerbás incluye una «nota preliminar» antes de cada novelita para afirmar la autenticidad de la autoría del texto que la sigue y del que él mismo sólo se responsabiliza en su condición de traductor. Las abundantes notas a pie de página abundan en tal planteamiento aunque una breve «Exculpación» añadida en la segunda tirada del libro sirve para que el autor hispano reconozca haber reelaborado sus ficciones a partir de los personajes inventados por tres autores ingleses

10 . Singularmente el procedimiento de humanización de los animales que recorre el texto, tal como se puede advertir en este apunte de la suerte final del toreo desde la perspectiva del protagonista: «Vio moverse el trapo.

Atacó.

Al principio, no sintió nada. Como si hubiera chocado con una mariposa. Luego, notó que algo caliente le quemaba la joroba. Los cisnes tienen alas -pensó-. Quizás me están saliendo» (Jorobita, p. 75). 
-Charles Dickens, Lewis Carroll y Arthur Conan Doyle- y excuse tanto la falsificación de tres dibujos de ilustradores ingleses $-\ll$ Phiz», Tenniel y Paget- que él mismo había ejecutado para la primera edición de Tres pastiches victorianos como los juicios eruditos que atribuye a un conjunto de críticos anglófonos expertos en los tres escritores imitados ${ }^{11}$.

El material paratextual de La vuelta al mundo en ochenta mundos ofrece todavía mayor complejidad. La dedicatoria a su madrina-«enferma imaginaria que viajaba sin moverse de su butaca»-explicaría, además de algunos reflejos autobiográficos que sobrenadan en la novela La inmortalidad del cangrejo, el despliegue de testimonios sobre la autenticidad del viaje relatado en este libro, testimonios que se exponen prolijamente en el «Prólogo», «Apéndice» e «Índices» y que, como señala el autor, «para garantizar la veracidad de este relato, debería bastar la palabra de honor de un caballero. No obstante, ya que ciertos sujetos se empeñan en privar de validez a mi testimonio personal, me permitiría aconsejarles que examinaran minuciosamente los diversos objetos, documentos y utensilios que fui recogiendo a lo largo de mi periplo». Al final, cuatro páginas no numeradas para que el lector escriba «Notas de lectura» siguen a un «Colofón» repleto de detalles.

Una «Relación pormenorizada de los objetos y documentos reunidos a lo largo de la circunnavegación del yate Mirto» y el dibujo de dos mapas que reflejan el recorrido de la embarcación son los testimonios de veracidad aducidos por el autor ${ }^{12}$. Algunos dibujos de estos testimonios que se reproducen en las páginas de La vuelta al mundo en ochenta mundos están firmados por «J. Isaac» aunque la mayoría reproducen grabados de otros artistas o de anónimos folletos publicitarios ${ }^{13}$. Ahora bien, el juego de las falsas atribuciones y de la erudición imaginada recibe un golpe de gracia

11. Los expertos dickensianos Edgard Jonson, y Martín Gardner, los conocedores de la obra de Lewis Carroll, Anne Clark y Helmut Gernsheim, y las reconocidas autoridades en Conan Doyle y su detective, Michael y Mollie Hardwick. La «Exculpación» aparece en la segunda edición de la obra, en la que se cambia el título por el de Pickwick, Alicia y Holmes al otro lado del espejo y se añaden los comentarios biográficos y críticos de Juan Tébar y Eduardo Torres-Dulce a los que antes he hecho mención..

12. Creo que, en un arranque de máxima simulación de la debatida veracidad del viaje, el escritordibujante podía haber reproducido las figuras de los objetos a los que alude del mismo modo que un viajero de la Ilustración, Leandro Frnández de Moratín, dibujó en el manuscrito de sus Apuntaciones del viaje a Inglaterra diversos objetos del país visitado que le llamaron la atención.

13. Por ejemplo, los dos grabados de Durero que se imprimen en las páginas 49 y 70 son trabajos del artista germano que Rodríguez Santerbás sitúa con precisión en la fuente de donde los toma (cf. The Complete Woodcuts of Albert Dürer, ed. Dr. Willi Kurth, New York, Dover Publications, 1963, p. 47 para «Catón instruye a su hijo en el lecho de muerte» y p. 112 para «Las siete trompetas son entregadas a los ángeles»). 
en el epílogo titulado «Acción de gracias», en el que Rodríguez Santerbás, después de aseverar que en este libro «ni creé a la mayoría de sus personajes, ni inventé todas las palabras que pronunciaron», relaciona las «Fuentes» de donde proceden los ochenta «azares» (así denomina a cada una de las aventuras o capítulos del volumen ${ }^{14}$ y los ochenta héroes que los pueblan y que, al tratarse de un periplo iniciado y concluido en Sevilla, comienza con el mítico don Juan y concluye con la evocación del cantaor decimonónico Silverio Franconetti. Todo un despliegue de cultura literaria y de guiños de culta complicidad con el lector imbuido en las tradiciones literarias más variadas.

\section{LA TÉCNICA DE LOS PASTICHES}

El principio universal de imitación, rector de la creación literaria, está en la base de los procesos de mimetización textual que, al modo de la «escritura oblicua» de la que ha hablado Philipe Hamon, da cuerpo a las parodias y los pastiches de las antiguas y las modernas literaturas ${ }^{15}$. El procedimiento que, en sus orígenes, tuvo una finalidad principalmente burlesca ha ido desplegando unos propósitos de índole lúdica tan acentuados que ha terminado por convertirse en un rasgo caracterizador de la literatura reciente. Por ejemplo, Patrick Rambaud, escritor francés especialista en la imitación del estilo de otros, obtuvo el premio Gouncourt por su novela histórica La Bataille (1997), un relato documentadísmo que rescribe la batalla de Essling al modo de los grandes novelistas históricos franceses del siglo XIX, comenzando por Balzac. En la novela española actual el pastiche es uno de los procedimientos más frecuentados y va desde la imitación del estilo de fórmulas novelescas populares -el folletín, la novela negra, la novela rosa- hasta la atribución de textos a autores que no los han escrito -pienso en la colección de Cuentos únicos (1989) de Javier Marías-.

El tributo a la cultura literaria que paga Santiago Rodríguez Santerbás alcanza en Tres pastiches victorianos su manifestación más ostentosa en el conjunto de componentes paratextuales que antes he mencionado y que pueden resultar reiterativos para un lector exigente, ya que el acierto de esta selección de tres falsas novelas -al modo de Ramón Gómez de la Ser-

14. Las referencias del fondo último de este libro de viajes y aventuras son, por supuesto, Verne y Costaza.

15. Para abreviar bibliografía, véanse la Introducción de Paola Mildonian a las Actas Parodia, Pastiche, Mimetismo. Atti del Convengo Internazionale di Letterature Comparate, Roma, Bulzoni, 1997. 
na- atribuidas a los escritores ingleses del siglo XIX Dickens, Lewis Carroll y Conan Doyle estriba en su hábil imitación de la estructura narrativa y el estilo de los creadores de Picwick, Alicia y Sherlock Holmes.

En «El último viaje de Mr. Pickwick» imagina Rodríguez Santerbás una nueva aventura que traslada al personaje de Dickens a la imaginada ciudad inglesa de Sarborough (la pertinente nota la identifica con Salisbury) para recuperar un cuadro de Rubens que donará a la galería de pinturas de Dulwich. En el viaje de búsqueda, acompañado de sus inevitables acólitos Sam Weller y Mr. Tupman, experimenta sobresaltos, engaños e incidentes muy similares a los que ocurrieron a los personajes en la novela original. En «Aventuras de Alicia en la cámara oscura», la protagonista del relato de Charles Lutwidge Dodgson vive una inquietante experiencia al convertirse en el negativo de una placa fotográfica y, en «Las aventuras del quinteto inacabado», el famoso detective y virtuoso violinista Sherlock Holmes coincide en el París fin de siècle con el español Sarasate para resolver el enigma de un asesinato que se produce en presencia de ambos. De manera que el moderno escritor español pone a prueba en su imitación el sugestivo decir descriptivo del costumbrista Dickens, la fantástica imaginación del profesor de Lógica que era capaz de ver «otra realidad» en el otro lado del espejo y la inteligencia inductiva del modélico narrador de novelas policíacas ${ }^{16}$.

Si la asimilación de los modelos narrativos originales está realizada con envidiable habilidad, un acierto análogo supone la imitación estilística. La expresión linguiística de las novelitas supuestamente traducidas produce un efecto de aceptación por parte del lector que, acostumbrado a las versiones más difundida de la prosa narrativa inglesa, no duda en recibir los textos falsos como otras tantas traducciones de tres escritos redactados originalmente en inglés. Por supuesto, Rodríguez Santerbás ha acreditado su competencia como traductor de textos literarios ingleses, pero en el caso de estos tres pastiches la imitación del «estilo original» echa mano de las convenciones más acreditadas en la práctica de la traducción de la literatura inglesa: el empleo de abundante adjetivación que sugiere asociaciones valorativas, la frecuencia de expresiones coloquiales de uso respetable o la construcción sintáctica ornamentada con meandros subordinantes. Valga el párrafo de una de las tres novelitas como muestra de esta práctica imitativa:

Hubo, al parecer, algunos pedantes y eruditos de tres al cuarto que se atrevieron a insinuar que Las Tres Gracias no habían nacido del pincel de Rubens, sino de

16. J. Vallés Calatrava incluye «Las aventuras del quinteto inacabado» en su relación de novelas policiacas españolas (La novela criminal española, Granada, 1991). 
la torpe brocha de un desmañado plagiario. Acaso porque tales maledicencias llegaron a oídos del donante, o quizás porque éste no lograra reponerse del catarro adquirido en la fatídica vigilia de Ringstone, el caso es que el estado de salud de Mr. Picwick se agravó repentina e inexorablemente, hasta el extremo de que, viéndose forzado a guardar cama y temiendo que aquella enfermedad pudiera llevarle a una inconsciencia definitiva, decidió hacer testamento, para lo cual encomendó a su mayordomo que requiriese la presencia de un honesto y escrupuloso abogado de la vecindad ${ }^{17}$.

La novelita de 1987 Román y yo apunta también a los juegos del pastiche aunque de forma más sutil y disfrazada ${ }^{18}$. Se trata de una narración en primera persona que enuncia la niña protagonista para dar cuenta de lo que le ocurre en el curso de un verano vivido con su abuela -autora de éxito de novelas rosa- en un pueblo marítimo. Allí, Alicia conoce a otros seres adultos y de su edad pero, singularmente al superviviente de una mordedura del conde Drácula, Román, del que se hace entrañable confidente y del que recibe el estigma que posee a la estirpe de vampiros a que dio origen el libro clásico de Bram Stoker; algunos pasajes de Román y yo recuerdan situaciones de Peter Pan mientras que otros funcionan como sarcástica alusión a las narraciones amorosas de una popular escritora asturiana de hace pocos años. La desazón que suscita la presencia de lo irreal, gracias a las limpidez del tono narrativo de este relato, toma cuerpo en las consideraciones que se va haciendo a sí misma la niña protagonista, como en esta que cierra la novela:

Han pasado varios meses, cuatro o cinco, desde que fui a casa de mi abuela y conocí a Román y hablé con él y vi su cadáver con una estaca en el corazón. Procuro portarme como una niña normal. Pero no soporto el olor de los ajos, y me mareo en las iglesias, y mi rostro no aparece en las fotografías ni se refleja en el cristal de los espejos.

¿Qué voy a hacer? ¿Tendré que irme a mi casa, sin que se enteren mis padres, y meterme en un ataúd, como Román, y dormir durante el día y salir por las noches en busca de ....alimento? ${ }^{19}$.

17. «El último viaje de Mr. Pickwick» en Pickwick, Alicia y Holmes..., p.73.

18. No pueden faltar los guiños culturalistas como la dedicatoria del libro - «Para Phocas cuando aprenda a leer»- que, con independencia del apelativo del niño a que se encamina, evoca el nombre del personaje inventado por el novelista decadente francés Jean Lorrain y que Rubén Darío retomaría en el soneto «A Phocás el campesino» de sus Cantos de vida y esperanza.

19. Román y yo, pp. 109-110. 


\section{LA NOVELA DEL TIEMPO ILIMITADO Y LOS ESPACIOS OBSESIVOS}

La inmortalidad del cangrejo (1985) es el relato de más aliento, por extensión y complejidad, que ha salido de la pluma de nuestro autor y que compendia su universo literario con una plasticidad notable. El solapamiento de realidad e irrealidad, la conciencia angustiosa de un tiempo y un espacio que sofocan el crecimiento de la vida, la acumulación, en fin, de muchas alusiones que, como ironías y homenajes, trazan un recamado de asociaciones culturales y literarias. Sólo la vista de los libros que reposan sobre la mesilla de noche de uno de los personajes orienta al lector acerca de este último recurso: «The Return of Sherlock Holmes, los Essais de Montaigne, las Epístolas familiares de fray Antonio de Guevara, los Pickwick Papers, los Soliloquios de Marco Aurelio en la edición bilingüe de Haines» ${ }^{20}$.

El relato, también en primera persona, de un joven profesor de Instituto describe la existencia enclaustrada de los miembros de la familia Hontanar, indemnes al paso del tiempo pero muy sensibles a los estímulos de los espacios en los que se mueven. Algunos no salen prácticamente de su vieja mansión, otros -como el más viejo de todos ellos- viajan incasablemente mientras el protagonista se limita a pasear las viejas rúas de una mortecina ciudad en cuya descripcións se adivina la natal del escritor ${ }^{21}$. Frente a la inmovilidad de unos, el movimiento incesante del viejísimo bisabuelo que da cuenta a sus parientes de los diversos lugares que visita -Viena, Venecia, Creta, París, Amsterdam, Kovenhavn, Edimburgo, Nueva York, Albi, Viena- para evocar en ellos las resonancias históricas y artísticas que suscitan en un viajero hiperculto. Y frente al tiempo ilimitado en el que este grupo humano chapotea con la Fuente de la vida -no en vano se llaman Hontanar y descienden de un añoso conquistador que anduvo en la Florida del siglo XVI a la búsqueda de la Fuente de la eterna juventud-, el narrador protagonista liquida con un pistoletazo suicida el diario que había comenzado el primero de enero del año anterior, con lo que el relato vuelve al punto de partida y cubre exactamente la duración de un año natural.

20. La inmortalidad del cangrejo, p. 42.

21. El tema modernista de las «ciudades muertas» ha vuelto a surgir en la narrativa reciente por la animación que presta a viejos centros urbanos la narrativa de un Luis Mateo Díez. En La inmortalidad del cangrejo son frecuentes las pistas identificatorias de la ciudad a que se alude, si bien la más pertinente es una descripción reiterada del paseo del protagonista: «Crucé el arco de San Miguel, fui caminando hasta el puente de la Estación bajo las ramas desnudas de los tilos, atravesé el río, que venía turbio y muy crecido, seguí por el paseo del Sotillo, desde donde se veían las torres gemelas de la catedral perfiladas contra el cielo incoloro, llegué a la plaza del Instituto, esquivé algunos corros de alumnos, franqueé el oscuro zaguán renacentista...» (p. 28) 
La falsa experiencia de una juventud prestada que domina a la familia Hontanar es rechazada por su más joven descendiente que, ante el estímulo de los jóvenes de verdad que son sus anodinos estudiantes, proclama:

\begin{abstract}
No quiero ser eternamente joven. Si pronuncié esas palabras, esa súplica negativa a nadie dirigida, fue porque, desde hacía años, sabía que no era lo mismo ser joven que poseer una juventud efectiva, pero artificial. Ser joven era gozar de la inexperiencia y sufrir por ella, descubrir día a día las turbadoras primicias el bien y del mal, presentir que todo lo que sucediera, habría de ser absolutamente nuevo y que, una vez acaecido, no volvería jamás a repetirse, porque la repetición equivalía a la madurez, a la experiencia, al desencanto y a la muerte ${ }^{22}$.
\end{abstract}

El venerable mito de Fausto viene en ayuda de esta vivencia profunda de la imposibilidad de la juventud ilimitada, pero no se trata del mito reelaborado por Goethe sino, en un quiebro de sutileza literaria, del Doctor Faustus de Marlowe, sobre el que uno de los Hontanar ha pergeñado una ópera zurcida con piezas musicales de muy distintos compositores. La promiscuidad musical de esta ópera corre en paralelo con la impresionante acumulación de citas textuales en varias lenguas, de alusiones a libros y autores de la Literatura Universal y de primorosos usos sociales de exquisitez cosmopolita escasamente practicados en la vieja ciudad que sirve de marco inmediato a la historia familiar y, en último término, al tiempo histórico español sobre el que se proyecta esta fábula sobre el tiempo y el espacio.

El culturalismo que se hacía notar en otros textos de Rodríguez Santerbás alcanza en esta novela su punto culminante del mismo modo que la intención irónica surge agazapada en casi todas sus páginas. Repárese en que el mismo título de la novela, al par que repite una frase hecha de la lengua conversacional señala al motivo heráldico de la singular y esperpéntica familia que la protagoniza. Culturalismo, ironización, sentimiento desazonado ante el correr del tiempo son algunos de los relieves más acusados de esta narración que no resultan, por otra parte, muy alejados de las emociones con que impregnaban su escritura narrativa los autores de la generación de nuestro novelista.

22. La inmortalidad del cangrejo, pp. 161-162. 


\section{OBRAS PUBLICADAS DE SANTIAGO RODRÍGUEZ SANTERBÁS}

Jorobita, prólogo de Miguel Delibes, Valladolid, Gerper, 1960, 76 pp.

Opúsculo de amenas y sustanciosas reflexiones sobre el arte de bien manducar, Burgos, Hijos de Santiago Rodríguez, 1967, 20 pp.

Tres pastiches victorianos; Madrid, Hiperión, 1981, 195 pp.

Reimpresión con añadidos en:

Pickwick, Alicia y Holmes al otro lado del espejo /Tres pastiches victorianos), introducción de Juan Tébar, apéndice de Eduardo TorresDulce Lifante, ilustraciones de José María Ponce y J. Isaac, Madrid, Anaya, 1996, 207 pp.

La vuelta al mundo en ochenta mundos. Edición profusamente ilustrada, diseño gráfico J. Isaac y Equipo 109, Madrid, Hiperión, 1982, 263 pp. +6 pp. sin numerar.

La inmortalidad del cangrejo, Madrid, Hiperión, 1985, 202 pp.

Román y yo, ilustraciones de José Pérez Montero, Madrid, Anaya, 1987, $111 \mathrm{pp}$.

Valdediós, (Gijón), 1987.

La doncella y el unicornio, ilustración de Sara y Elena R. Chamón, Madrid, Anaya, 1989, 44 pp. 